\title{
Maternal and fetal outcome in antepartum haemorrhage: a study at tertiary care hospital
}

\author{
Kshama Kedar, Prashant Uikey, Ashwini Pawar, Anuja Choudhary*
}

\begin{abstract}
Department of Obstetrics and Gynaecology, Indira Gandhi Govt. Medical College and Hospital, Nagpur, Maharashtra,
\end{abstract} India

Received: 18 April 2016

Accepted: 25 April 2016

\section{*Correspondence:}

Dr. Anuja Choudhary,

E-mail: dranuja.choudhary@gmail.com

Copyright: (C) the author(s), publisher and licensee Medip Academy. This is an open-access article distributed under the terms of the Creative Commons Attribution Non-Commercial License, which permits unrestricted non-commercial use, distribution, and reproduction in any medium, provided the original work is properly cited.

\begin{abstract}
Background: Antepartum hemorrhage (APH) complicates about 2-5\% of pregnancies. Maternal and perinatal morbidity and mortality associated with APH can be reduced significantly by aggressive expectant management. The objective was to study the maternal and fetal outcome in APH and to assess the importance of early diagnosis and treatment

Methods: This prospective study was conducted in the department of OBGY in IGGMC Nagpur from Dec 2013 to Nov.15. 131 cases of APH with gestational age $>28$ weeks were included. They were distributed according to type of APH into Abruptio Placentae (AP), Placenta Previa (PP) and Unclassified Haemorrhage (UH). Causes of APH were noted and maternal as well as perinatal outcome observed.

Results: Out of 131, 51.91\% was AP followed by PP (45.80\%) and 2.29\% of UH. Maximum patients belonged to 25 to 29 years age group $(40.46 \%$ ), which was statistically significant (p value 0.023 ). Maximum no. of patients who presented with APH was of more than 36 weeks of gestational age which was statistically significant ( $p$ value 0.0001). 52.94\% had PIH as a causative factor of abruption while $41.67 \%$ had history of previous LSCS for PP. Anaemia was most common complication in APH followed by PPH. One patient died of renal failure in AP. Neonatal jaundice was the most common complication amongst the neonate followed by prematurity.

Conclusions: Prevalence of APH was $2 \%$ with AP being most common cause followed by PP. Though maternal morbidity is reduced with modern management of APH, but timely diagnosis and intervention is necessary.
\end{abstract}

Keywords: Antepartum haemorrhage, Abruptio placentae, Placenta previa

\section{INTRODUCTION}

Antepartum hemorrhage (APH) has always been one of the most feared complications in obstetrics. Vaginal bleeding at any stage of pregnancy is a matter of great concern for patient as well as her doctor. Antepartum hemorrhage is still a grave obstetric emergency contributing to a significant amount of maternal and perinatal morbidity and mortality in our country.

Hemorrhage is one of the leading causes of maternal mortality and morbidity. According to centre for disease control and prevention, hemorrhage was a direct cause of maternal death in about $30 \%$ of cases. APH can be due to placenta previa, abruptio placentae, indeterminate cause or local causes. Antepartum hemorrhage (APH) complicates about $2-5 \%$ of all the pregnancies, with incidence of Placenta previa (PP) about $0.33 \%^{1}$ to $0.55 \%^{2}$ and incidence of Abruptio placentae (AP) about $0.5-1 \%{ }^{3}$

The maternal complications in patients with APH are malpresentation, premature labor, postpartum hemorrhage (PPH), sepsis, shock and retained placenta. Various fetal complications are premature baby, low birth weight, intrauterine death, congenital malformation and birth asphyxia. ${ }^{4}$ Maternal mortality due to APH has 
significantly decreased in developed countries to about 6/100000 live births due to better obstetrical outcome. In India, maternal mortality is still very high and is 4.08/1000livebirths. ${ }^{5}$ In developing countries widespread pre-existing anemia, difficulties with transport, restricted medical facilities, decreased awareness on part of patient and relatives are largely responsible for high MMR (Maternal Mortality Rate). Perinatal mortality is less than 10 per 1000 total births in developed countries while it is much higher in India 60/1000 total births. ${ }^{5}$ Although APH cannot be prevented but maternal and perinatal morbidity and mortality associated with APH can be reduced significantly by aggressive expectant management. Presently increasing use of ultrasonography (USG) for placental localisation and to diagnose abruptio placentae, improved obstetrical and anesthetic facilities, increasing use of blood and its products to correct anemia and advanced neonatal care facilities to make increased chances of survival of a preterm infant, all collectively have played important role in decreasing perinatal as well as maternal morbidity and mortality. ${ }^{6}$ For APH during Pregnancy all obstetricians with timely and aggressive treatment will go a long way in further reducing the maternal and fetal morbidity and mortality. This study is to evaluate how far we have come and the effect of treatment on the perinatal and maternal outcome.

\section{Aims and objectives}

Aim

- To study the causes of Antepartum Hemorrhage.

- To study the maternal and fetal outcome in Antepartum Hemorrhage.

- To assess the importance of early diagnosis and treatment.

\section{Study objective}

- To study the prevalence of antepartum hemorrhage at tertiary care hospital.

- To emphasize the importance of early diagnosis and prompt treatment in the improvement of maternal and perinatal outcome.

- To determine the cause of APH.

- To assess the value of current obstetric practice in managing APH.

\section{METHODS}

\section{Study design}

It is a prospective study which was conducted in OPD and Emergency, Obstetrics and Gynecology department, IGGMC and Mayo Hospital, Nagpur.

\section{Sample size and participants}

All consenting females who presented with APH in the Antenatal OPD \& in emergency, over a period of two years from December 2013 to November 2015 (131 cases).

\section{Inclusion criteria}

- All cases of APH with gestational age $>28$ weeks.

\section{Exclusion criteria}

- All cases of APH with gestational age <28 weeks.

- Patient suffering from any other bleeding disorder.

- Bleeding from a source other than uterus.

\section{Methodology}

On admission, a complete history including history of present complaint, obstetric history, menstrual history, past history, family history was taken. Information regarding her age, address, socioeconomic status and dietary habits was noted. Special enquiry was made regarding smoking and drug use, history regarding her previous antenatal checkups was noted.

General physical examination was done to assess both maternal and fetal condition. Abdominal examination, per speculum and per vaginum examination (when required) was done.

All patients presenting with APH were initially investigated and managed as outlined below, but subsequent management was determined according to the suspected cause, severity and type of bleeding and the gestational age of the pregnancy.

The initial management included the following:

- An intravenous line with a wide bore cannula was established.

- Blood samples were obtained for immediate hemoglobin and hematocrit estimation, complete blood count and for grouping and cross matching; and sent to laboratory. Bleeding time, clotting time and clot retraction time were done at bed side.

- Intravenous fluids were given according to severity of bleeding and patient's general condition, while cross matched blood was awaited.

- USG was done to establish the cause of APH, when maternal and fetal conditions were stable.

After this initial management, the further management was based on following criteria

- $\quad$ The bleeding had stopped.

- The bleeding was continuing but remained mild and nonlife threatening. 
- The bleeding was continuing and was severe and life threatening.

- The fetus was in distress, irrespective of the bleeding pattern.

- There was fetal demise.

The subsequent management, based on the above factors was divided into,

- Immediate delivery

- Expectant management

These were carried out according to the suspected cause of $\mathrm{APH}$, based on the history, examination and investigations.

If PP and AP were excluded, rest of the patients with APH were placed under Unclassified hemorrhage (UH) and further management depended on gestational age, nature of bleeding (persistent or recurrent and severity), the state of the fetus (absence or presence of fetal distress and the cause) and cause of bleeding.

The majority of the benign causes of genital bleeding (vulvar lesions cervical erosions, cervical polyps, vaginitis and vulvovaginal varicosities) and cervical carcinoma were excluded by gentle visual examination of the lower genital tract with the speculum. The conditions were treated accordingly.

\section{Data analysis}

Statistical analysis was done using EPI INFO software. The Fisher's exact test and Chi sq. test was done to determine the significance of difference between the groups. The significance level for the study was $p<0.05$.

\section{RESULTS}

The present study was carried out on 131 patients who presented with APH in the Antenatal OPD \& in emergency, over a period of two years from December 2013 to November 2015.

Table 1: Distribution of patient according to cause of APH.

\begin{tabular}{|lll|}
\hline Type of APH & Frequency & Percent \\
\hline Abruptio placentae & 68 & 51.91 \\
\hline PP & 60 & 45.80 \\
\hline Unclassified haemorrhage & 3 & 2.29 \\
\hline Total & 131 & 100
\end{tabular}

Majority (52\%) of patients had AP while $46 \%$ had PP.

Table 2: Booked V/S unbooked patients.

\begin{tabular}{|ll|l|}
\hline Type of APH & Booked $(\%)$ & Unbooked (\%) \\
\hline Abruptio placentae & $21(30.88)$ & $47(69.11)$ \\
\hline PP & $24(40)$ & $36(60)$ \\
\hline $\begin{array}{l}\text { Unclassified } \\
\text { Hemorrhage }\end{array}$ & $1(33.34)$ & $2(66.67)$ \\
\hline Total & 46 & 85 \\
\hline
\end{tabular}

85 patients of APH were unbooked as compared to 46 who were booked. Maximum numbers of AP were unbooked $(69.11 \%)$. This was found to be significant ( $p$ value 0.559 , Chi square test).

Maximum no. of patients of APH belonged to 25 to 29 years age group $(40.46 \%)$ which was found to be statistically significant ( $\mathrm{p}$ value 0.023 , chi square test).

APH was more common in multipara than in nullipara. Mean parity was $1.6 \pm 1.3$.

Table 3: Distribution of patients according to age group (in years).

\begin{tabular}{|llllll|}
\hline Type of APH & $20-24(\%)$ & $25-29(\%)$ & $30-34(\%)$ & $>35(\%)$ & Total \\
\hline Abruptio placentae & $13(19.11)$ & $19(27.94)$ & $22(32.35)$ & $14(20.58)$ & $68(100)$ \\
\hline Placenta previa & $14(23.33)$ & $32(53.34)$ & $10(16.67)$ & $4(6.67)$ & $60(100)$ \\
\hline Unclassified hemorrhage & $0(0)$ & $2(66.67)$ & $1(33.34)$ & $0(0)$ & $3(100)$ \\
\hline Total & 27 & 53 & 33 & 18 & 131 \\
\hline
\end{tabular}

Table 4: Distribution of patients according to parity.

\begin{tabular}{|llllllll|}
\hline Type of APH & P0 $(\%)$ & P1 $(\%)$ & P2 $(\%)$ & P3 (\%) & P4 (\%) & P5 (\%) & Total \\
\hline Abruptio placentae & $15(22.05)$ & $28(41.17)$ & $14(20.58)$ & $7(10.29)$ & $1(1.47)$ & $3(4.41)$ & $68(100)$ \\
\hline PP & $8(13.34)$ & $25(41.67)$ & $22(36.67)$ & $5(8.34)$ & $0(0)$ & $0(0)$ & $60(100)$ \\
\hline Unclassified hemorrhage & $2(66.67)$ & $0(0)$ & $0(0)$ & $0(0)$ & $1(33.34)$ & $0(0)$ & $3(100)$ \\
\hline Total & 25 & 53 & 36 & 12 & 2 & 3 & 131 \\
\hline
\end{tabular}


Table 5: Gestational age at time of admission (weeks).

\begin{tabular}{|llllll|}
\hline Type of APH & $<28(\%)$ & $29-32(\%)$ & $33-36(\%)$ & $>36(\%)$ & Total \\
\hline Abruptio placentae & $1(1.47)$ & $7(10.29)$ & $19(27.94)$ & $41(60.29)$ & $68(100)$ \\
\hline PP & $1(1.67)$ & $2(3.34)$ & $23(38.33)$ & $34(56.67)$ & $60(100)$ \\
\hline Unclassified hemorrhage & $0(0)$ & $0(0)$ & $2(66.67)$ & $1(33.34)$ & $3(100)$ \\
\hline Total & 2 & 9 & 44 & 74 & 131 \\
\hline
\end{tabular}

Table 6: According to fetal heart sound.

\begin{tabular}{|lllll|}
\hline Type of APH & $\begin{array}{l}\text { Absent } \\
(\%)\end{array}$ & $\begin{array}{l}\text { Positive } \\
(\%)\end{array}$ & $\begin{array}{l}\text { Fetal } \\
\text { distress } \\
(\%)\end{array}$ & Total \\
\hline $\begin{array}{l}\text { Abruptio } \\
\text { placentae }\end{array}$ & $\begin{array}{l}21 \\
(30.88)\end{array}$ & $33(45)$ & $\begin{array}{l}14 \\
(20.58)\end{array}$ & $\begin{array}{l}68 \\
(100)\end{array}$ \\
\hline PP & $9(15)$ & $45(75)$ & $6(10)$ & $\begin{array}{l}60 \\
(100)\end{array}$ \\
\hline $\begin{array}{l}\text { Unclassified } \\
\text { hemorrhage }\end{array}$ & $0(0)$ & $3(100)$ & $0(0)$ & $\begin{array}{l}3 \\
(100)\end{array}$ \\
\hline Total & 30 & 81 & 20 & 131 \\
\hline
\end{tabular}

Maximum patients of APH were more than 36 weeks period of gestation $(56.49 \%)$. Out of this maximum patients were of Abrutio placentae and placenta previa, which was found to be significant ( $\mathrm{p}$ value 0.0001 , chi square test).

30 patients of APH had absent fetal heart sound at time of admission. Out of these, 21 cases were of AP. Among 20 patients who had fetal distress at time of admission 14 belonged to abruptio.

\section{Previous LSCS}

30 patients of APH had history of previous LSCS and 25 belonged to PP group. This was found to be significant ( $\mathrm{p}$ value 0.001 , chi square test).

\section{Previous $D$ and $C$}

There was a history of $\mathrm{D}$ and $\mathrm{C}$ in 7 patients of $\mathrm{PP}$.

Table 7: Associated factors.

\begin{tabular}{|llll|}
\hline $\begin{array}{l}\text { Associated } \\
\text { factors }\end{array}$ & $\begin{array}{l}\text { Abruptio } \\
\text { placentae } \\
(\%)\end{array}$ & $\begin{array}{l}\text { Placenta } \\
\text { previae } \\
(\%)\end{array}$ & $\begin{array}{l}\text { Unclassified } \\
\text { hemorrhage } \\
(\%)\end{array}$ \\
\hline Nil & $7(10.29)$ & $8(13.34)$ & $1(33.34)$ \\
\hline Anemia & $16(23.51)$ & $16(26.67)$ & $1(33.34)$ \\
\hline PIH & $36(52.94)$ & $3(5)$ & $1(33.34)$ \\
\hline Prev D\&C & $2(2.94)$ & $7(11.67)$ & $0(0)$ \\
\hline Prev LSCS & $5(7.35)$ & $25(41.67)$ & $0(0)$ \\
\hline PROM & $2(2.94)$ & $1(1.67)$ & $0(0)$ \\
\hline Total & $68(100)$ & $60(100)$ & $3(100)$ \\
\hline
\end{tabular}

Table 8: Mode of delivery.

\begin{tabular}{|llll|}
\hline Type of APH & LSCS (\%) & $\begin{array}{l}\text { Vaginal } \\
\text { delivery } \\
(\%)\end{array}$ & Total \\
\hline $\begin{array}{l}\text { Abruptio } \\
\text { placentae }\end{array}$ & $30(44.11)$ & $38(55.88)$ & $68(100)$ \\
\hline PP & $56(93.33)$ & $4(6.67)$ & $60(100)$ \\
\hline $\begin{array}{l}\text { Unclassified } \\
\text { hemorrhage }\end{array}$ & $0(0)$ & $3(100)$ & $3(100)$ \\
\hline Total & 86 & 45 & 131 \\
\hline
\end{tabular}

Table 9: Indication of caesarean section in relation to cause of APH.

\begin{tabular}{|lllll|}
\hline Indication of LSCS & Abruptio placentae (\%) & Placenta previa (\%) & Unclassified hemorrhage $(\%)$ & Total \\
\hline Elective & $0(0)$ & $29(51.78)$ & $0(0)$ & 29 \\
\hline Fetal distress & $12(46.15)$ & $9(16.07)$ & $0(0)$ & 21 \\
\hline Hemorrhage & $13(50)$ & $17(30.35)$ & $0(0)$ & 30 \\
\hline Transverse Lie & $1(1.78)$ & $1(1.78)$ & $0(0)$ & 2 \\
\hline Total & 26 & 56 & 0 & 82 \\
\hline
\end{tabular}

\section{Pre-eclampsia}

36 patients of AP were associated with pregnancy induced hypertension as compared to 3 patients of PP which was statistically significant ( $\mathrm{p}$ value 0.034 , chi square test).
Maximum patients of APH delivered by caesarean section $(65.64 \%)$ as compared to vaginal delivery (34.35\%). $56(93.33 \%)$ patients of PP group underwent caesarean section whereas $30(44.11 \%)$ patients from AP underwent caesarean section. This was found to be significant ( $\mathrm{p}$ value 0.0001 , chi square test). 
Table 10: Maternal outcome.

\begin{tabular}{|lllll|}
\hline Maternal outcome & $\begin{array}{l}\text { Abruptio placentae } \\
(\%)\end{array}$ & $\begin{array}{l}\text { Placenta previa } \\
(\%)\end{array}$ & $\begin{array}{l}\text { Unclassified hemorrhage } \\
(\%)\end{array}$ & Total \\
\hline Nil & $5(7.35)$ & $5(8.34)$ & $2(66.67)$ & 12 \\
\hline Anemia & $29(42.64)$ & $33(55)$ & $0(0)$ & 62 \\
\hline Couvellaire & $7(10.29)$ & $0(0)$ & $0(0)$ & 7 \\
\hline Caesarean section hysterectomy & $0(0)$ & $1(1.67)$ & $0(0)$ & 1 \\
\hline PPH & $25(36.76)$ & $16(26.67)$ & $1(33.33)$ & 42 \\
\hline Renal Failure & $1(1.47)$ & $0(0)$ & $0(0)$ & 2 \\
\hline Scar Dehiscence & $0(0)$ & $2(3.34)$ & $0(0)$ & 3 \\
\hline Sepsis & $0(0)$ & $3(5.00)$ & $0(0)$ & 1 \\
\hline UTI & $1(1.47)$ & $0(0)$ & $0(0)$ & 131 \\
\hline Total & $68(100)$ & $60(100)$ & $3(100)$ & 2 \\
\hline
\end{tabular}

Table 11: Perinatal outcome.

\begin{tabular}{|lllll|}
\hline Morbidity & Abruptio placentae & PP & Unclassified hemorrhage & Total \\
\hline Normal & 62 & 32 & 2 & 96 \\
\hline Birth asphyxia & 0 & 1 & 0 & 1 \\
\hline Hyaline membrane disease & 0 & 1 & 0 & 1 \\
\hline Neonatal jaundice & 0 & 21 & 0 & 21 \\
\hline Prematurity & 6 & 5 & 1 & 12 \\
\hline Total & 68 & 60 & 3 & 131 \\
\hline Fetal weight & & & 67 \\
\hline Low birth weight (\%) & $46(67.64)$ & $20(33.34)$ & $1(33.34)$ & 64 \\
\hline Normal (\%) & $22(32.35)$ & $40(66.66)$ & $2(66.66)$ & 131 \\
\hline Total & $68(100)$ & $60(100)$ & $3(100)$ & 114 \\
\hline Fetal mortality & & & 1 \\
\hline Number & 54 & 57 & 3 & 14 \\
\hline Birth asphyxia & 0 & 1 & 0 & 2 \\
\hline Still birth and early neonatal death & 14 & 0 & 0 & 131 \\
\hline RDS & 0 & 2 & 0 & 3 \\
\hline Total & 68 & 60 & 3 & \\
\hline
\end{tabular}

The commonest indication for caesarean section in abruption and PP was hemorrhage followed by fetal distress in abruptio placentae. In 29 patients of PP elective caesarean section was done.

\section{Maternal mortality}

There was only one maternal death in this study group. The patient had grade III AP was admitted in a state of hemorrhagic shock. There was sudden shut down of renal system. Patient died because of renal failure.

Anemia was the most common complication in APH patients followed by postpartum hemorrhage (PPH). $42.64 \%$ patients of AP had anemia as compared to $55 \%$ patients of PP. In case of AP 25 patients had PPH as compared to 16 patients with placenta previae. One patient died because of renal failure in abruptio placentae.
Couvellaire uterus was present in 7 patients of abruptio placentae. 3 patients of PP had sepsis. 2 patients of PP had scar dehiscence. 1 patient of AP underwent caesarean hysterectomy.

Neonatal jaundice was the most common complication amongst the neonate of APH followed by prematurity, birth asphyxia and hyaline membrane disease.

Prematurity was the most common outcome seen in AP whereas neonatal jaundice was the most common outcome in PP.

46 babies of AP were low birth weight out of 67 babies. There were 7 still births and 7 early neonatal death in abruptio placentae. 


\section{DISCUSSION}

In the day to day practice, an obstetrician has to tackle life threatening condition of APH and take a timely judicious decision of terminating pregnancy, keeping in mind the welfare of both the mother and the fetus without exposing either of them to undue risk.

In the present study incidence of various causes of APH was noted. The causes were determined clinically in antenatal period and during the delivery. Incidence of abruption placentae was largest $51.91 \%$ followed by PP $45.80 \%$ and few were of unclassified hemorrhage $2 \%$.

Table 12: Study distribution of antepartum hemorrhage according to cause (\%) PP and abruptio placentae, unclassified hemorrhage.

\begin{tabular}{|llll|}
\hline & PP & $\begin{array}{l}\text { Abruption } \\
\text { placenta }\end{array}$ & $\begin{array}{l}\text { Unclassified } \\
\text { hemorrhage }\end{array}$ \\
\hline $\begin{array}{l}\text { Amoma (1992) } \\
\text { Chakraborty }\end{array}$ & 44 & 33 & 19 \\
$(1993)^{8}$ & 54 & 35 & 19 \\
\hline Present study & 45.80 & 51.91 & 2 \\
\hline
\end{tabular}

The results of the present study are indicative of increased incidence of abruptio placenta $(51.91 \%)$ and PP $(45.80 \%)$ probably because of unregistered cases, low socioeconomic strata, anemia, Asian origin and prevalence of previous caesarean section, D \&C and increased incidence of pregnancy induced hypertension.

However, the incidence of PP is lower in western literature. Taylor et al observed higher incidence of PP in women of Asian origin. ${ }^{9}$

To study the effect of antenatal care on maternal and fetal outcome in Abruptio placentae, patients were divided into booked and unbooked. Patient without a single ANC visit was labeled as unbooked and patients who had a one or more ANC checkups in our hospital were labeled as booked. In present study $84.52 \%$ patients were unbooked as compared to $45.77 \%$ patients who were booked. Out of these unbooked cases AP comprised $69.11 \%$ and PP comprised $36 \%$ where as in unclassified hemorrhage two patients were unbooked. Rai et $\mathrm{al}^{10}$ in his study also reported more number of AP cases were unbooked. The importance of antenatal visits in prevention of AP has also been stated by Baskette et $\mathrm{al}^{11}$ who reported that in their series $3 / 4^{\text {th }}(75 \%)$ of cases were unbooked.

Increasing age has been implicated as a predisposing factor in both PP and Abruptio placentae.

In the present study mean age of patients of APH was 2529 years. Mean age of AP patient was 30-35 years, in PP patients mean age was 25-29 years and in Unclassified hemorrhage it was found to be 25-29 years. Incidence of AP was found to increase from 19.11\% (age group 20-24 years) to $32.35 \%$ (age group 30-34 years). Pedowitz et $\mathrm{al}^{12}$ and Das et $\mathrm{al}^{13}$ have also reported maximum number of cases in the same age group. Ananth et $\mathrm{al}^{14}$ found increased incidence of placenta previa with advancing age. William et $\mathrm{al}^{15}$ also reported increased risk of AP with advancing age.

In the present study it was observed that the incidence of APH was more common in multipara than in nullipara and the mean parity was $1.6 \pm 1.3$. The incidence of PP was 5 times higher in multipara than primipara. Chakraborty et $\mathrm{al}^{8}$ reported that prevalence of APH was higher among multigravidas. Results of present study are consistent with study of Cotton et $\mathrm{al}^{16}$ who found that $83.2 \%$ of their patients with PP were multiparous and $16.78 \%$ were nulliparous. Crenshaw et al $^{17}$ reported that $10 \%$ patients with PP were primi gravida. Ananth et al ${ }^{14}$ showed that risk of placental abruption increased with high parity.

FHS (fetal heart sound) indicates fetal well-being. Absence of FHS or evidence of fetal distress ${ }^{18}$ was important in gauging the condition of fetus and the obstetric management of patient partially depended on this. In present study 81 cases $(61.83 \%)$ with APH, FHS was normal at the time of admission while evidence of fetal distress was noted in 20 cases (15.26\%). In 30 cases $(22.90 \%)$ FHS was absent at the time of admission. In 33 cases $(45 \%)$ of AP, FHS was normal, 21 cases $(30.88 \%)$ had absent FHS and 14 cases $(20.58 \%)$ had evidence of fetal distress at admission. This was found to be statistically significant as compared to Unclassified hemorrhage (UH) group in which all cases had normal FHS at admission.

In PP group 45 cases (75\%) had normal FHS, 9 cases (15\%) had absent FHS and 6 cases $(10 \%)$ had fetal distress at admission. The results of the study are similar to that of Chakraborty et $\mathrm{al}^{8}$ who reported that normal FHS was present in $66 \%$ of all patients of APH. In their series $72.56 \%$ of PP patients and $82.7 \%$ of UH patients had normal FHS. FHS was absent in $33.33 \%$ of AP patients. In their study evidence of fetal distress was present in $26.08 \%$ patients with AP.

In present study 30 cases of APH had a history of previous LSCS. H/O prior LSCS was found in 25 cases $(41.67 \%)$ of PP patients as compared to 5 cases $(7.37 \%)$ of AP. This is comparable to study of Gilliam et $\mathrm{al}^{19}$ and Taylor et $\mathrm{al}^{9}$ who found that $20 \%$ cases and $15 \%$ cases of PP respectively in their studies had a history of previous caesarean section.

The present study showed that 7 cases $(11.67 \%)$ of PP had a previous history of abortion which is consistent with study of Taylor et $\mathrm{al}^{9}$ who found that $30 \%$ patients of PP had a previous history of abortion. 2 cases of AP patients had a history of previous abortion. Hibbard et $\mathrm{al}^{20}$ reported an increased incidence of AP in woman with $\mathrm{h} / \mathrm{o}$ of previous abortion. 
Incidence of PROM was found to be in 3 cases of APH patients in this study. 2 cases $(2.94 \%)$ in AP group and 1 case $(1.67 \%)$ in PP group had H/O PROM. Major et $\mathrm{al}^{21}$ reported an increased incidence of AP in cases of PROM.

In present study 40 patients with APH had hypertensive disorders of pregnancy. 36 patients $(52.94 \%)$ with abruptio placentae, 3 patients $(7.5 \%)$ with PP and 1 patient with UH had pregnancy induced hypertension. Hibbard et al 20 found hypertensive disorders of pregnancy complicating $7.4 \%$ patients with APH. Rai et $\mathrm{al}^{10}$ found $4.4 \%$ incidence of hypertensive disorders of pregnancy in APH patients.

In PP, 4 patients $(6.67 \%)$ were delivered vaginally and 56 patients $(93.33 \%)$ were delivered by Caesarean section. Of all the patients of Abruptio placentae, 38 cases $(55.88 \%)$ delivered vaginally and 30 cases $(44.11 \%)$ delivered by caesarean section. All obstetricians agree that early and timely caesarean section improve perinatal salvage in patients with abruption placentae. ${ }^{22}$ In the unclassified hemorrhage group there was no perinatal death in present study.

The indication for Caesarean section was studied according to causes of APH. In present study commonest indication of caesarean section was hemorrhage 13 cases followed by fetal distress (12 cases). Malpresentation was cause for Caesarean section in $1 \%$ of APH patients. Elective Caesarean section was done in a total of 29 patients of PP. In PP, 29 elective LSCS were for major degrees of PP (type IV, III, IIb) \& 3 CS were done for CPD in cases of type IIa PP.

Cotton et al $^{16}$ reported hemorrhage as an indication for caesarean section in $70.6 \%$ of patients of APH in their study.

One of the main aim of proper management of APH cases is to minimize the maternal mortality and morbidity. Anemia was the most common complication in APH \& was seen in 33 patients of PP and 29 patients of abruption placentae. Postpartum hemorrhage was the $2^{\text {nd }}$ most common complication \& was seen in 41 cases of APH (25 patients of AP\& in 16 patients of PP). Chakraborty et $\mathrm{al}^{8}$ reported an incidence of $16.25 \% \mathrm{PPH}$ in cases of APH. In PP group, one patient $(2.5 \%)$ had placenta accreta who underwent caesarean hysterectomy. Pedowitz et $\mathrm{al}^{12}$, Cotton et $\mathrm{al}^{16}$ and McShane et $\mathrm{al}^{23}$ reported the incidence of placenta accreta as $4.4 \%, 4 \%$ \& $6.32 \%$ respectively. In abruption placenta group couvellaire uterus was seen in $2(3.6 \%)$ cases. Rai et al ${ }^{10}$ reported couvellaire uterus in $10.5 \%$ of $\mathrm{APH}$ patients in their study.

One maternal death occurred in present study. Patient had grade III Abruption placenta \& died due to renal failure. Gorodeski et $\mathrm{al}^{24}$ reported maternal mortality of $0.46 \%$ in APH while Pedowitz et $\mathrm{al}^{12}$ reported it as $0.9 \%$. Cotton et $\mathrm{al}^{16}$ found no mortality in cases of PP in their study.
One of the major aspects of this study was to study the perinatal outcome in various groups of APH. Neonatal jaundice was the most common complication in APH, followed by prematurity and birth asphyxia. In PP, 21 neonate had neonatal jaundice. Prematurity was commonly seen in abruption placentae. 6 neonates were premature. 2 neonate had respiratory distress syndrome. 46 babies of AP were low birth weight out of 67 babies and out of 60 babies, 20 babies of PP were low birth weight. 7 early neonatal deaths and 7 still births occurred in abruptio placentae.

\section{CONCLUSIONS}

APH is still the leading cause of maternal morbidity. Prevalence of APH in our hospital is $2 \%$. The most common cause of APH is AP followed by PP.

Though maternal morbidity is reduced with modern management of APH, but timely diagnosis \& intervention is necessary.

Most of the patients were unbooked (84.52\%), \& multiparous which suggest their careless attitude towards pregnancy \& not taking antenatal care. Pregnancy induced hypertension is a most common cause of AP $(52.94 \%)$ which reflects poor antenatal care. It should be made mandatory for all primary health centers to identify such high risk patient at their level \& timely refer to tertiary care centers. Previous history of D\&C (11.67\%) $\&$ caesarean section $(41.67 \%$ ) were the biggest cause of $\mathrm{PP}$, which prove its theory of adherence to scar.

Fetal outcome varies with the gestational age; out of 68 women of abruption only 7 were still birth and 7 were early neonatal deaths due to severe prematurity. No mortality was seen in PP group.

\section{"Stitch in Time Saves Nine"}

Routine antenatal check-up, timely referral, timely caesarean section, liberal blood transfusion, correction of anemia and wider acceptance of expectant line of management in tertiary centre with availability of blood transfusion and good neonatal intensive care unit will help further to lower the perinatal and maternal morbidity and mortality.

\section{Funding: No funding sources}

Conflict of interest: None declared

Ethical approval: The study was approved by the Institutional Ethics Committee

\section{REFERENCES}

1. Crane JMG, Van Den Hof MC, Dodds L, Armson BA, Liston R. Neonatal outcomes with placenta previa. Obstetr Gynecol. 1999;93:541-4. 
2. Frederiksen MC, Glassenberg R, Stika CS: Placenta previa: a 22-years analysis. Am J Obstetr Gynecol. 1999;180:1432.

3. Ananth CV, Smulian JC, Vintzileos AM. Incidence of placental abruption in relation to cigarette smoking and hypertensive disorders during pregnancy: A meta-analysis of observational studies. Obstetr Gynecol. 1999;93:622-8.

4. Cunningham F, Leveno K, Bloom S, Hauth J, Gilstrap L, Rouse D et al. Obstetrical haemorrhage. Williams Obstetrics. 23rd Edition, New York, McGraw Hill Professionals;2009.

5. Park K. Maternal and child health. In: Park's textbook of preventive and social medicine. $17^{\text {th }}$ edition. Banarasi Das Bhanot 'Jabalpur; 2000.

6. Dutta DC. Antepartum haemorrhage. In: Hiralal Konar, editor. Textbook of obstetrics. $6^{\text {th }}$ edition. New Central Book Agency, Calcutta; 2004:243-61.

7. Amoma AB, Augerea L, Klufio CA. Late pregnancy bleeding. PNG Med J. 1992;3517.

8. Chakraborty B De KC, Evaluation of third trimester bleeding with reference to maternal and perinatal outcome. J Obstetr Gynecol India. 1993;42:166-71.

9. Taylor VM, Peacock S, Kramer MD, Vaughan TL. Increased risk of placenta previa among women of Asian origin. Obstetr Gynecol. 1995;86(5):805-8.

10. Rai L, Duvvi H, Rao UR, Vaidehi, Nalinii V. Severe abruptio placentae Still unpreventable Int J Gynecol Obstetr. 1989;29:117.

11. Baskette TF. Grand multiparity- a continuing threat: a 6 year review. Can Med Assoc J. 1997;116:1001.

12. Pedowitz P. Placenata previa; an evaluation of expectant management and the factors responsible for fetal wastage. An J Obstetr \& Gynecol. 1965;93:16-25.

13. Das B. Antepartum haemorrhage in three decades. J Obstetr \&Gynecol India. 1975:25:636-7.

14. Ananth CV, Wilcox AJ, Savitz DA, Bowes WA Jr, Luther ER. Effect of maternal age and parity on the risk of uteroplacental bleeding disorders in pregnancy. Obstetr \& Gynecol. 1996;88(4 Pt 1):5116.

15. William MA, Mittendorf R. Increasing maternal age, a determinant for placenta previa more important than increasing parity. PJ Report Med. 1993;38:4258.

16. Cotton DB, Read JA, Paul RH, Quilligan EJ. The conservative aggressive management of placenta previa. Am J Obstetr Gynecol. 1980;137:687.

17. Crenshaw C Jr, Jones DE, Parker RT. Placenta previa: a survey of twenty years experience with improved perinatal survival by expectant 119 therapy and Cesarean delivery. Obstetr Gynecol Surv. 1973;28(7):461-70.

18. Alfirevic Z, Roberts D, Martlew V. How strong is the association between maternal thrombophilia and adverse pregnancy outcome? a systematic review. Eur J Obstetrics \& Gynecology Reprod Biol. 2002;101:6-14.

19. Gilliam M, Rosenberg D, Davis F. The likelihood of placenta previa with greater number of cesarean deliveries and higher parity. Obstetr \& Gynecol. 2002;99:976.

20. Hibbard BM, Jeffcoate TNA. Abruptio Placentae. Obstetr Gynecol. 1966;27:155-67.

21. Major CA, de Veciana M, Lewis DF, Morgan MA. Preterm premature rupture of membranes and abruptio placentae: Is there an association between these pregnancy complications? Am J Obstetrics \& Gynecol. 1995;172:672-6.

22. Kayani SI, Walkinshaw SA, Preston C. Pregnancy outcome in severe placental abruption. Br J Obstetr Gynaecol. 2003;110:679-83.

23. Mc Shane SP, Epstein MF. Maternal and perinatal morbidity resulting from placenta previa. Obstetr \& Gynecol. 1985;65:176-81.

24. Gorodeski IG. Bahari CM. Schachter A, Neri A. Recurrent placenta previa. Eur J Obstetr Gynecol Reprod Biol. 1981;12(1):7-11.

Cite this article as: Kedar K, Uikey P, Pawar A, Choudhary A. Maternal and fetal outcome in antepartum haemorrhage: a study at tertiary care hospital. Int J Reprod Contracept Obstet Gynecol 2016;5:1386-93. 